\title{
Collision tumour of ovary: a rare combination of fibrothecoma with serous cystadenoma
}

\author{
Archana Mishra ${ }^{1 *}$, Saritha Shamsunder ${ }^{1}$, Sunita Malik ${ }^{1}$, Sufian Zaheer ${ }^{2}$
}

${ }^{1}$ Department of Obstetrics and Gynecology, ${ }^{2}$ Department of Pathology, Vardhman Mahavir Medical College and Safdarjung Hospital, Delhi, India

Received: 05 January 2017

Accepted: 04 February 2017

*Correspondence:

Dr. Archana Mishra,

E-mail: drarchanamishra@rediffmail.com

Copyright: ( $)$ the author(s), publisher and licensee Medip Academy. This is an open-access article distributed under the terms of the Creative Commons Attribution Non-Commercial License, which permits unrestricted non-commercial use, distribution, and reproduction in any medium, provided the original work is properly cited.

\begin{abstract}
A collision tumour is defined by presence of two separate tumors in one organ on gross, microscopic and immunehistochemical studies without any admixture. These tumors are reported from oesophagus, stomach, liver, lung and thyroid glands. Such tumors are extremely rare in ovary. In case of ovaries most common histological collision reported between mucinous tumors and teratomas. We are reporting a rare combination of fibrothecoma with serous cystadenoma in right ovary of a premenopausal woman. Both gynaecologist and pathologist should be aware of such combination. It is important to differentiate such tumors from malignant ovarian tumors. Frozen section and scrape cytology are important tools which help in appropriate management of such cases intraoperatively.
\end{abstract}

Keywords: Collision tumour, Fibrothecoma, Frozen section, Serous cystadenoma

\section{INTRODUCTION}

A collision tumour is defined by presence of two separate tumours in one organ on gross, microscopic and immunohistochemical studies without any admixture. ${ }^{1}$ These tumours are reported from oesophagus, stomach, liver, lung and thyroid glands. Such tumours are extremely rare in ovary. ${ }^{2}$ Most common combination is a collision between carcinoma and sarcoma or carcinoma and lymphoma.

Some rare combinations between two carcinomas have also been reported. In case of ovaries most common histological collision reported between mucinous tumours and teratomas. ${ }^{2} \mathrm{We}$ are reporting a rare combination of Fibrothecoma with Serous Cystadenoma in right ovary of a premenopausal woman.

\section{CASE REPORT}

A 43 year old woman presented to us with history of pain in lower abdomen for 3 years and mass in lower abdomen for last 2 years. Pain was not associated with any bowel or bladder complaints, weight loss, breathlessness, fever or night sweats. Her menstrual cycle was regular with heavy flow. There was no significant past, family or medical history. Her general and systemic examination was unremarkable. Abdominal examination revealed a large central cystic mass of $18-20 \mathrm{~cm}$ present in the suprapubic region which was mobile and non-tender. There was no hepatosplenomegaly. Pelvic examination revealed an anteverted multiparous uterus with large, ill defined, soft and cystic 18-20 cm mobile and non-tender mass which was palpable in right and posteior fornix. Trans abdominal ultrasound revealed a uterus of normal morphology. Right adnexa showed a complex cystic mass 
lesion with solid component of variegated appearance left ovary was normal. MRI revealed a mass with clearly defined large cystic component of about 57x50x76 mm and large solid component of $71 \times 35 \times 65 \mathrm{~mm}$ with nonvisualization of right ovary. Suspicion of malignant ovarian tumor was expressed (Figure 1).

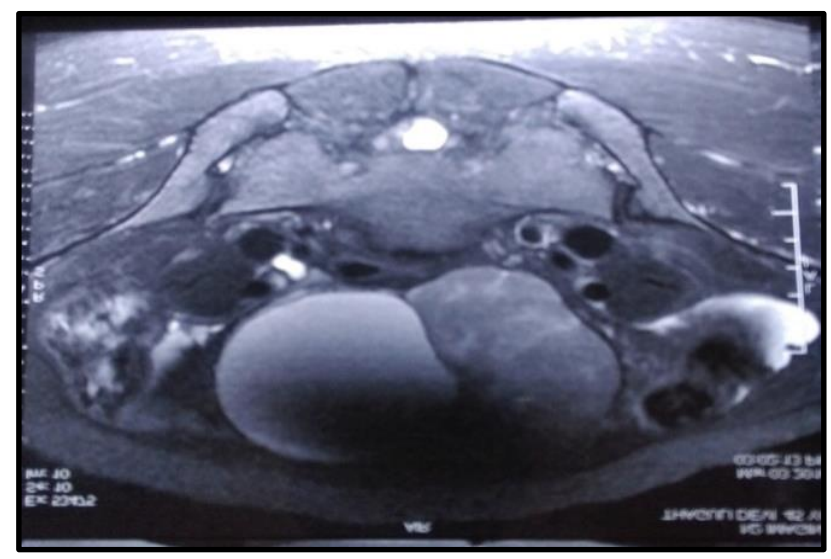

Figure 1: MRI of ovarian tumour showing right half cystic and left half solid.

All the tumor markers like CA-125, CEA and LDH were within normal limits. Endometrial biopsy revealed secretory endometrium. On laparotomy we found a pearly white lobulated hour glass shaped mass with solid and cystic components and intact capsule. Solid component measured 7x5x4.6 cm and cystic component measured 6 $\mathrm{cm}$ in diameter. Solid components had prominent vessels on it and cystic component had translucent wall and clear fluid in it. Capsule was smooth and intact (Figure 2).

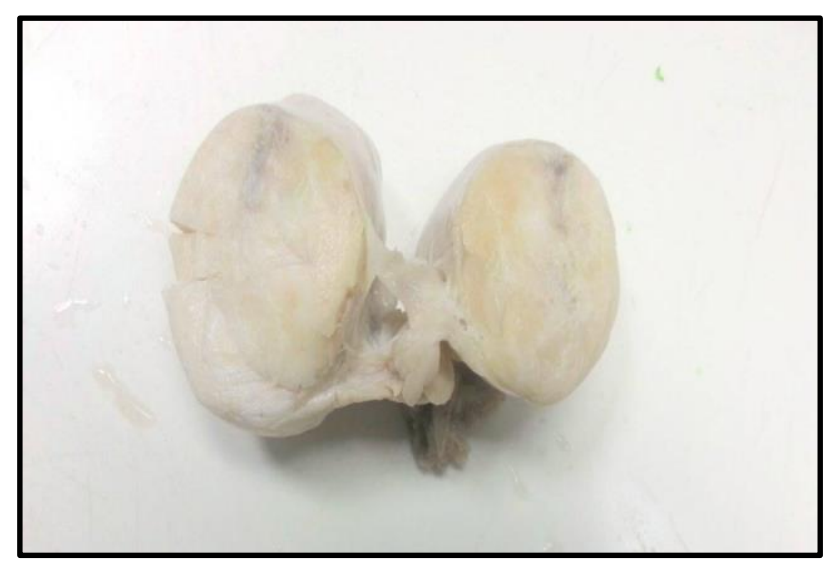

Figure 2: Greyish white solid tumor with intact capsule and cyst wall.

Specimen was sent for scrape cytology as facility of frozen section was not available in our set up. It revealed the combination of serous cystadenoma with fibrothecoma. Pelvic lymphadenectomy was not done in view of benign nature of tumour. Histopathology of the specimen revealed wall thickness was 0.1 to $0.2 \mathrm{~cm}$. Cyst was unilocular filled with serous fluid .There were no areas of haemorrhage, necrosis, hair, tooth, cartilage, bone or glandular elements seen. Solid component was showing mainly spindle shaped cells present in cohesive clusters and fragments. These cells had oval to spindle shaped nuclei with indistinct nuclei. No cellular pleomorphism or mitotic activity could be identified. Cystic component revealed nests of transitional epithelium (urothelial cells) (Figure 3). There was sharp demarcation between two tumors. Findings were suggestive of collision of serous cystadenoma with benign sex cord stromal tumour fibrothecoma.

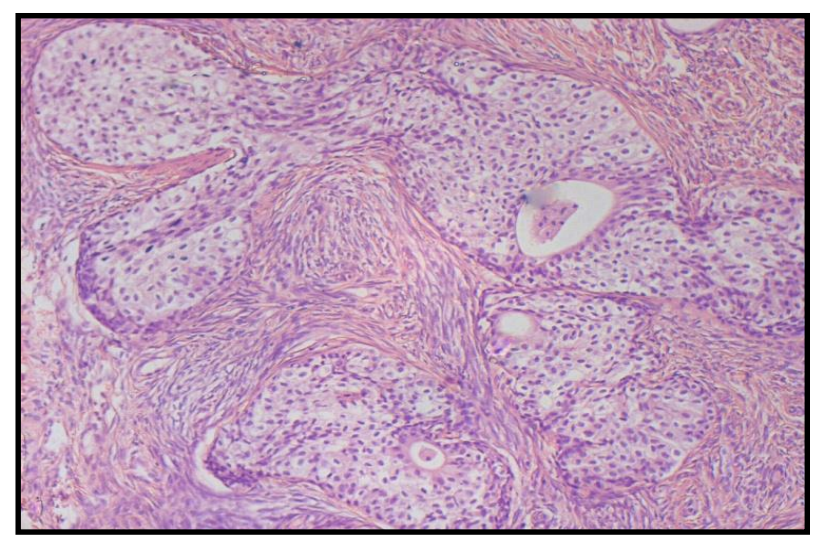

Figure 3: Microphotograph showing nests of transitional epithelial (urothelial) cells lying in abundant fibrous stroma (H and E 10x).

\section{DISCUSSION}

Collision tumours are two primary neoplasm occurring in the same organ. Symptoms and management usually depends upon individual biological aggressiveness of each component of tumour. These tumours should be differentiated from malignant mixed mullerian tumours which are also known as composite tumours. There is intermingling of tumour lines in composite tumours. ${ }^{3}$ There are many hypothesis associated with origin of collision tumour. It could be due to coincidental occurrence of two different cell lines growing in the same tissue. ${ }^{4}$ Other possible hypothesis is origin of 2 different cell lines from a common precursor pleuripotent stem cell. $^{5}$ Other hypothesis suggested is of alteration of microenvioronment due to effect of carcinogenic agents of primary tumours or oncogenic growth factors of metastatic tumours. ${ }^{6}$ Review of literature revealed one more case of collision tumour of ovary with histology of Fibrothecoma and serous Cystadenoma. ${ }^{7}$ Variegated appearance of collision tumour often gives a false impression of malignant ovarian neoplasm. Fibroma and thecoma usually merge to form fibrothecoma. Ovarian fibrothecoma is a solid ovarian tumour, which may mimic malignant tumour. Ascites and pleural effusion may be present in some cases which is known as Meig's Syndrome. It falsely gives an impression of inoperable malignant neoplasm. Serous cystadenoma usually present as unilocular or multilocular ovarian cysts which are lined by coloumnar epithelium. Malignant potential of fibrothecoma is $2 \%$ and Serous Cytadenoma is only 
$0.7 \% .^{8,9}$ Importance of differentiating a collision tumour from malignant neoplasm is due to impact of the diagnosis on clinical management. A majority of collision tumors are diagnosed postoperatively on histopathology although radiology may provide a clue. Diagnosis should be made intra-operatively so that unnecessary morbidity associated with extensive lymphadenectomy could be prevented. Intraoperative analysis by frozen section and scrape cytology is important in such cases as it can very well differentiate between benign collision tumors from malignant neoplasm.

\section{CONCLUSION}

Both gynaecologist and pathologist should be aware of such combination. It is important to differentiate such tumours from malignant ovarian tumours. Frozen section and scrape cytology are important tools which help in appropriate management of such cases intraoperatively.

Funding: No funding sources

Conflict of interest: None declared

Ethical approval: Not required

\section{REFERENCES}

1. Singh A, Singh M. Collision tumours of ovary: a very rare case series. J Clin Diagn Res. 2014;8(11):FD14-6.

2. Bige O, Demir A, Koyuncuoglu M, Secil M, Ulukus C, Saygili U. Collision tumor: serous cystadeno carcinoma and dermoid cyst in the same ovary. Arch Gynecol Obstet. 2009;279:767-70.
3. Lewin K. Carcinoid tumour and mixed (composite) glandular-endocrine cell carcinomas. Am J Surg Pathol. 1987;11:71-86.

4. Nirenberg A, Ostor AG, Quinn MA. Collision tumor: serous adenocarcinoma and steroid cell tumor of the ovary. Pathol. 1992;24:60-2.

5. Mayur B, Kanthan CH, Rani K. Collision tumor of the colonic adenocarcinoma and ovarian granulosa cell tumor-case report. World Journal of Surgical Oncology. 2007;5:118.

6. Cohen A, Geller SA, Horowitz I, Toth LS, Werther JL. Experimental models for gastric leiomyosarcoma: the effects of N-methyl-N'-nitro-Nnitrosoguanidine in combination with stress, aspirin, or sodium taurocholate. Cancer. 1984;53:1088-92.

7. Chandanwale S, Pal S, Kumar H, Sammi A. Serous cystadenoma and fibrothecoma: a rare combination in collision tumor of ovary with pseudo-meigs syndrome. J Pathol Translat Medic. 2015;49:163-6.

8. Cho YJ, Lee HS, Kim JM, Lee SY, Song T, Seong SJ, Kim ML. Ovarian-sparing local mass excision for ovarian fibroma/fibrothecoma in premenopausal women. Europ J Obstets Gynecol Reproduc Biol. 2015;185:78-82.

9. Marana R, Muzii L, Catalano GF, Caruana P, Oliva C, Marana E. Laparoscopic excision of adnexal masses. J Am Assoc Gynecol Laparosc. 2004;11:162-6.

Cite this article as: Mishra A, Shamsunder S, Malik S, Zaheer S. Collision tumour of ovary: a rare combination of fibrothecoma with serous cystadenoma. Int J Reprod Contracept Obstet Gynecol 2017;6:1643-5. 